\section{SOI: $1.1 /$ TAS DOI: 10.15863/TAS International Scientific Journal Theoretical \& Applied Science}

p-ISSN: 2308-4944 (print) e-ISSN: 2409-0085 (online)

Year: $2018 \quad$ Issue: 09 Volume: 65

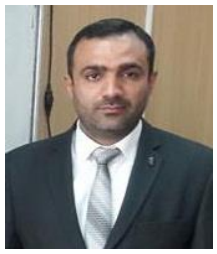

Hussien Abid Ali Bakir

$(\mathrm{PhD})$

University of Kufa,

Faculty of Science, Dept. of Physics

hussien_zahed@yahoo.com

hussein.mraity@uokufa.edu.iq

Ali Jaafar Azeez
University of Kufa,

Ali Jaafar Azeez
University of Kufa,

Ali Jaafar Azeez
University of Kufa,

SECTION 20. Medicine.

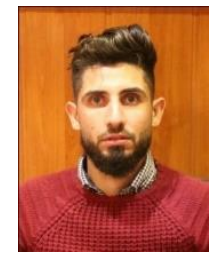

\title{
ASSESSMENT OF PATIENT'S DOSE DURING AP PELVIS RADIOGRAPHIC EXAMINATION IN SELECTED HOSPITALS OF AL NAJAF CITY, IRAQ
}

\begin{abstract}
Background: Protecting patients reproductive organs from unnecessary radiation is paramount during anterior-posterior (AP) pelvis radiography. Therefore, assessing patients' dose is necessary to ensure that the doses are within recommended levels.

Objective: This work is aimed at investigating patients' radiation dose undergoing AP pelvis x-ray examination in selected hospitals of Al Najaf.

Material and Method: Patients' doses were assessed for 93 patients. The Entrance Surface Dose (ESD) was calculated through the knowledge of X-ray tube output and exposure factors. The X-ray output was measured using a calibrated dosimeter for each X-ray tube. Seven X-ray tubes were used to assess the patients' ESD. Exposure factors (e.g. tube potential $(k V p)$, tube loading $(m A s)$ and $X$-ray source to image detector distance-SID $(\mathrm{cm}))$ were recorded for each patient. This data was used to calculate the ESD taken into account the backscatter factor. Four main hospitals were selected in this study, namely, Al Sadder (ASTH)), Al Hakeem (AHGH), Al Furat (AFH) and $\mathrm{Al}$ Zahraa $(\mathrm{AZH})$.

Results: The mean ESD value for AP pelvis X-ray examination was ranged from $0.81 \pm 0.16 \mathrm{mGy}$ to $3.4 \pm 0.36$ $m G y$ across all hospitals. The corresponding means of each of $k V p$ used for this examination was ranged from 73.3 to $87.3 \mathrm{kVp}$; mAs: ranged from 13.6 to $35.38 \mathrm{mAs}$ and for the SID the range was between 100 and $123.07 \mathrm{~cm}$. The value of max/min of the ESD was ranged from 1.5 to 3.3 across different hospitals

Conclusion:

The results demonstrate a clear variation in patient dose and exposure factors set among the selected hospitals. These values (i.e. ESD) were seen to be slightly comparable to those values of the UK (Survey-2010, 3.2 $m G y)$ and were higher than those reported by certain countries (e.g. Iran, Sudan etc.). Therefore, a periodic checking together with conducting a quality control testing is highly recommended.
\end{abstract}

Key words: ESD, AP pelvis, Patient dosimetry, Radiation safety, Radiation protection

Language: English

Citation: Abid Ali Bakir H, Azeez AJ (2018) ASSESSMENT OF PATIENT'S DOSE DURING AP PELVIS RADIOGRAPHIC EXAMINATION IN SELECTED HOSPITALS OF AL NAJAF CITY, IRAQ. ISJ Theoretical \& Applied Science, 09 (65): 45-52.

Soi: http://s-o-i.org/1.1/TAS-09-65-8

Doi: crossef https://dx.doi.org/10.15863/TAS.2018.09.65.8

\section{Introduction}

Increasing the knowledge concerning the hazards associated with exposure of patient to low doses of ionizing radiations during diagnostic X-ray examinations impose the need for radiation dose assessment [1]. In this regards, a number of organizations that specialized in the radiation protection have issued recommendations which aimed to reduce the patients' doses to its lowest levels. These include organizations such as the International Commission on Radiological
Protection-ICRP [2], International Atomic Energy Agency (IAEA)[3], and European Commission, 2000. Imaging of different body parts necessitate that different radiographic techniques must be adopted to meet the requirement of X-ray attenuation which, in turn, include different exposure levels especially for those thick parts that requires high dose for a proper penetration such as in AP pelvis radiography [4]. Nevertheless, it should be noted that the pelvic region include the gonads which are considered to be one of the most radiosensitive organs in the body [3]. This means that, during pelvic X-ray examination, 
the reproductive organs are inevitably exposed to the primary beam of X-ray and, therefore, the risk of inducing cancer within next generations does exist [5]. According to the literature, AP pelvis together with hip radiography has been reported to be the $3^{\text {rd }}$ most frequent X-ray examination when compared with the biggest dose contribution examinations in the United Kingdom, with a 39/1000 of population annual frequency [6]. Therefore, protecting patients gonads from unnecessary radiation dose is paramount during anterior-posterior (AP) pelvis radiography. Measurement of patient dose during AP pelvis X-ray examination was one of the aims of many researches [7-10]. However, other research attempts were conducted to minimize the patient dose during AP pelvis radiographic examination through optimizing its radiographic practice [11-13]. Optimization means finding an approach through which the dose can be reduced while maintaining the quality of the X-ray image acceptable for diagnosis [14]. One of most common and reliable dosimetric quantities used in diagnostic radiography to give an indicator for patient dose is the entrance surface dose (ESD). This quantity includes the contribution of backscatter radiation in the range of diagnostic X-ray (i.e. 40 to $150 \mathrm{keV}$ ) [15]. Assessment of patient dose undergoing routine radiographic examinations and specifically the AP pelvis X-ray projection has not been given the required attention that recommended by radiation protection organizations in Iraq and in Al Najaf in specific. Hence, this study is aimed at investigating the patient dose undergoing AP pelvis projection in selected hospitals of Al Najaf using indirect based dosimeric approach (i.e. depend on the knowledge of X-ray output measurements)

\section{Material and methods}

This study was undertaken in selected hospitals of $\mathrm{Al}$ Najaf city, Iraq; these include $\mathrm{Al}$ Sadder teaching hospital (ASTH), Al Hakeem general hospital (AHGH), Al Zahraa (AZH) and Al Furat Al Ausit hospitals (AFAH)). These hospitals were selected because they were covered the whole center of the city. Seven X-ray tubes were involved in this work. Before work was started, an ethical approval was obtained from the Al Najaf Health Administration of Al Najaf city. The research began by collecting information about the X-ray units; this includes X-ray tube manufacturer, model, year of installation and the type of the X-ray system (i.e. computed or digital radiography- CR/DR). These data are listed in table 1.

This table presents the X-ray systems information considered in this research.

Table 1.

\begin{tabular}{|c|c|c|c|c|}
\hline Hospital & Manufacturer & model & $\begin{array}{c}\text { Year of } \\
\text { installation }\end{array}$ & System types (DR/CR) \\
\hline ASTH & Siemens/Germany & AL01C & 2017 & DR \\
\hline AHGH (1)* & Shimadzu/Japan & R-20J & 2006 & CR \\
\hline AHGH (2) ${ }^{* *}$ & Shimadzu/Japan & R-20J & 2006 & CR \\
\hline AZH (1) & Shimadzu/Japan & R-20J & 2015 & CR \\
\hline AZH (2) & Shimadzu/Japan & R-20J & 2006 & CR \\
\hline AFAH(1) & Shimadzu/Japan & R-300 & 2005 & CR \\
\hline AFAH (2) & Shimadzu/Japan & 1/2P13DK & 2012 & CR \\
\hline
\end{tabular}

* and ** Refer to the room numbers in a given hospital.

Following this, demographic data were collected for all patients enrolled in this study, this includes patients' weight $(\mathrm{kg})$, height $(\mathrm{cm})$ and gender (male/female); these data were used to calculate the body mass index $\left(B M I=\mathrm{kg} / \mathrm{cm}^{2}\right)$ for individual patient. A minimum number of 10 patients ( $\geq 18$ years) was considered for each X-ray unit [16]. This led to 93 patients in total (male and female) to be enrolled.

Prior to the dose calculation, exposure/physical factors were recorded for individual patient and $\mathrm{X}$ - ray projection. These include $\mathrm{kVp}$ (peak tube voltage), mAs (milli amper. second) and and X-ray source to image detector distance-SID $(\mathrm{cm})$. The latter parameters are necessary to calculate the ESD $(\mathrm{mGy}=\mathrm{J} / \mathrm{kg})$. The ESD is the absorbed dose in air on the X-ray beam axis at a point where the beam is just entering the skin of the patient. The ESD calculation includes the backscatter contribution. The ESD was then calculated using the following equation $[17,18]$

$$
E S D(m G y)=\text { output }\left(\frac{m G y}{m A s}\right) \times\left(\frac{k V p}{80}\right)^{2} \times\left(\frac{100 \mathrm{~cm}}{F S D}\right)^{2} \times m A s \times B S F
$$


where output is the X-ray tube output factor in $\mathrm{mGy} / \mathrm{mAs}$ measured at a standard distance of $100 \mathrm{~cm}$ from the X-ray tube focus and $80 \mathrm{kVp}$ normalized to $10 \mathrm{mAs}, \mathrm{kVp}$ is the peak tube potential, mAs is the product of the tube current $(\mathrm{mA})$ and exposure time (sec), FSD is the focus to patient surface (skin) distance $(\mathrm{cm})$. The FSD was calculated by subtracting the patient thickness $(\mathrm{cm})$ from the SID. Patient thickness used in this work was sourced from perry et al [19] since measuring patient thickness directly during workload is difficult and might cause some inconvenience for the patients. The BSF is the backscatter factor and a value of 1.35 is usually used in diagnostic range [19].

The X-ray output (R/mAs) was measured using Rad-Check Plus model 06-526 X-ray exposure meter (Nuclear Associates, Victoreen Division, NY, USA) at $80 \mathrm{kVp}, 10 \mathrm{mAs}$ and $100 \mathrm{~cm}$ distance from tube focus (see figure 1). Three measurements were taken to allow the calculation of average value and to reduce random error. A $8.7 \mathrm{mGy} / \mathrm{R}$ conversion factor was applied to convert the output from $\mathrm{R}$ (Roentgen) to $\mathrm{mGy}$ in air (i.e. $1 \mathrm{R}=8.7 \mathrm{mGy}$ ) [20]. The ESD was finally calculated for all patients.

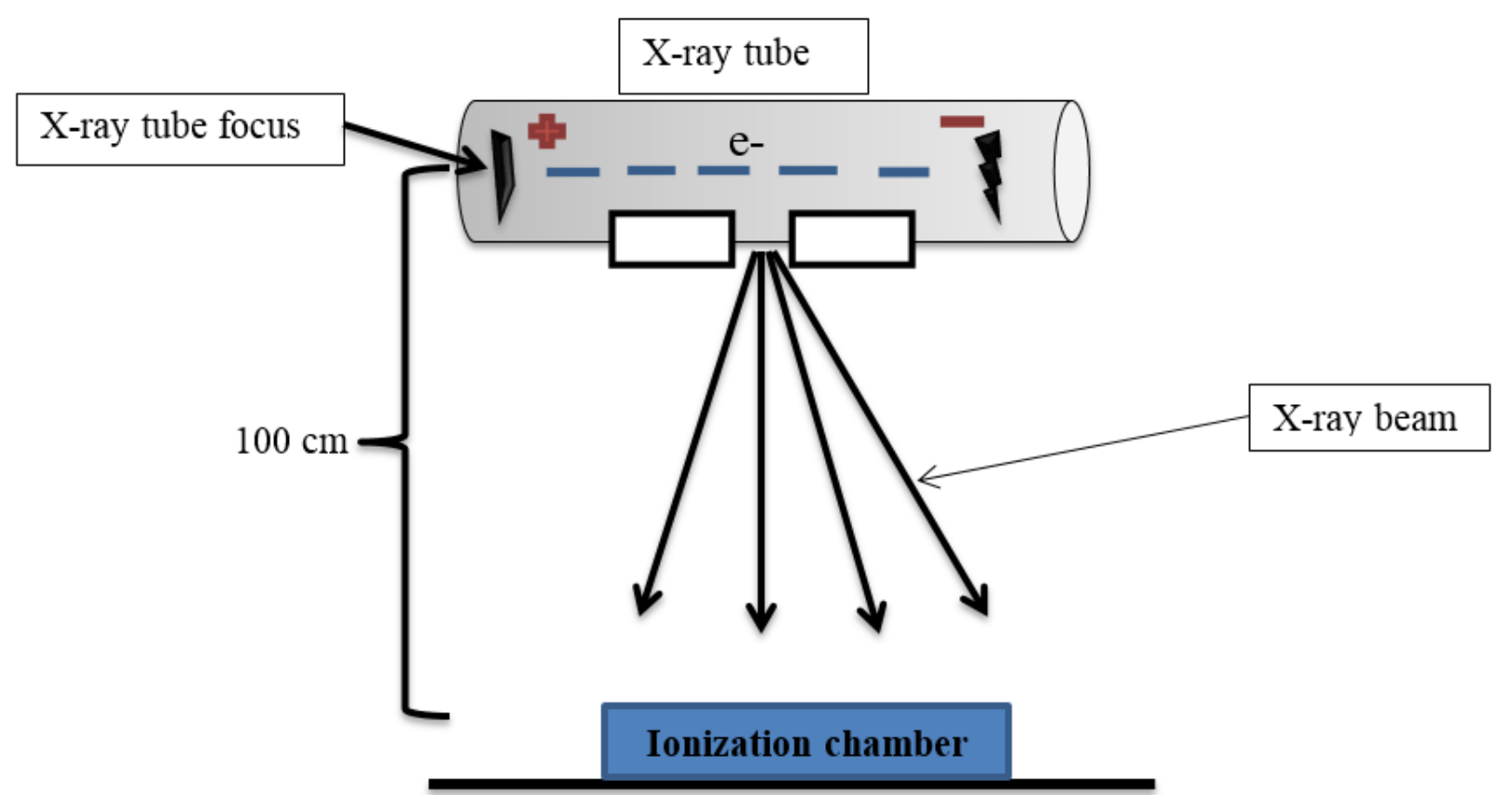

Figure 1. A schematic diagram illustrates the procedure of measuring X-ray output.

\section{Results}

Ninety three patients who were examined for AP pelvis radiography were recorded in this study. The study data were sourced from four hospitals in Al Najaf city. These hospitals include seven X-ray units. Patient demographic data are presented in table
(2). From table (2), it is clear that the average patients' weight $(\mathrm{kg})$ is ranged from $73 \pm 6.3$ to $80.6 \pm 5.6 \mathrm{~kg}$. The average patients' heights are ranged from $1.65 \pm 0.09$ to $1.69 \pm 0.08 \mathrm{~cm}$.

Weight (kg), height (m) and the BMI for patients examined for AP pelvis radiographic examination study.

\begin{tabular}{|c|c|c|c|}
\hline $\begin{array}{c}\text { Hospital } \\
\text { code }\end{array}$ & $\begin{array}{c}\text { Weight }(\mathrm{kg}) \\
\text { Average }(\mathrm{SD})\end{array}$ & $\begin{array}{c}\text { Height }(\mathrm{m}) \\
\text { Average (SD) }\end{array}$ & $\begin{array}{c}\text { BMI }\left(\mathrm{kg} / \mathrm{m}^{2}\right) \\
\text { Average }(\mathrm{SD})\end{array}$ \\
\hline ASTH & $80.6(5.6)$ & $1.69(0.08)$ & $28.07(2.8)$ \\
\hline AHGH $(1)^{*}$ & $76.5(5.1)$ & $1.69(0.10)$ & $26.90(2.7)$ \\
\hline AHGH (2) $)^{* *}$ & $75.3(7.02)$ & $1.66(0.08)$ & $27.2(3.01)$ \\
\hline AZH (1) & $75.07(6.6)$ & $1.65(0.10)$ & $27.8(4.77)$ \\
\hline AZH (2) & $73.30(6.3)$ & $1.65(0.09)$ & $27.05(3.03)$ \\
\hline AFAH(1) & $79.00(5.5)$ & $1.66(0.07)$ & $28.5(3.20)$ \\
\hline AFAH (2) & $76.10(6.7)$ & $1.67(0.07)$ & $27.3(3.40)$ \\
\hline BMI: Body mass index & \\
\hline
\end{tabular}


The BMI for all patients of this research is ranged from 27.05 to 28.07 , this in turn indicates for a relative homogeneity of the sample size in term of the weight and length. Nevertheless, patients' weight $(\mathrm{kg})$ and height $(\mathrm{m})$ variations are expected due to the natural variability of the population of the current governorate. By contrast, the average weight $(\mathrm{kg})$ of sample size considered in the UK was around $70 \mathrm{~kg}$ and this reflects the cultural variability of different population $[6,20]$.

The X-ray output values (mGy) normalized to $10 \mathrm{mAs}$ for the seven X-ray units presented in table (3). From this table, it can be seen that the highest tube output was measured at $\mathrm{AFAH}$ (1) at 0.063 $\mathrm{mGy} / \mathrm{mAs}$ and the lowest $(0.031 \mathrm{mGy} / \mathrm{mAs})$ was recorded at $\mathrm{AZH}$ - room (1).

Table 3.

This table lists the X-ray tube output factors measured at the seven X-ray units of the four hospital

\begin{tabular}{|c|c|}
\hline Hospital code & $\begin{array}{c}\text { X-ray tube output } \\
\text { (mGy/mAs) }\end{array}$ \\
\hline ASTH & 0.041 \\
\hline AHGH (1) & 0.061 \\
\hline AHGH (2) & 0.046 \\
\hline AZH (1) & 0.031 \\
\hline AZH (2) & 0.040 \\
\hline AFAH(1) & 0.063 \\
\hline AFAH (2) & 0.053 \\
\hline $\begin{array}{l}\text { * and ** represent the number of the room in a } \\
\text { given hospital }\end{array}$ \\
\hline
\end{tabular}

Tables (4) and (5) present the exposure factors applied to patients undergoing AP pelvis X-ray examinations and the corresponding ESD (mGy) calculated across the seven X-ray units. From table (4), it can be seen that that the minimum tube potential $(\mathrm{kVp})$ used was at AHGH (2) with 73.07 $\mathrm{kVp}$ while the highest values was reported in ASTH at $87.3 \mathrm{kVp}$. The range of $\mathrm{kVp}$ reported in this study is comparable to those that reported in UK [6] (e.g. Average; 75 - Range 62-90 kVp).

Table 4.

This table presents the average and range values of the exposure factors (kVp, mAs and SID) applied for AP pelvic X-ray projection across the studied hospitals.

\begin{tabular}{|c|c|c|c|}
\hline Hospital code & $\begin{array}{c}\text { Tube potential } \\
(\mathbf{k V p})\end{array}$ & $\begin{array}{c}\text { Tube loading } \\
(\mathbf{m A s})\end{array}$ & SID (cm) \\
\hline ASTH & $87.3(80-95)$ & $13.6(12-16)$ & $123.07(120-130)$ \\
\hline AHGH (1) & $73.3(65-80)$ & $30.9(24-40)$ & $100.7(100-110)$ \\
\hline AHGH (2) & $73.07(70-82)$ & $32.15(24-40)$ & $102.3(100-110)$ \\
\hline AZH (1) & $78.6(75-86)$ & $28.9(19-40)$ & $106.15(100-110)$ \\
\hline AZH (2) & $82(76-86)$ & $35.38(22-46)$ & $106.9(100-110)$ \\
\hline AFAH(1) & $80.6(80-82)$ & $18.4(16-24)$ & $100.0(100-100)$ \\
\hline AFAH (2) & $80.6(80-82)$ & $19.3(16-24)$ & $100.0(100-100)$ \\
\hline * and * represent the number of the room in a given hospital \\
\hline
\end{tabular}

The minimum and the maximum tube loading (mAs) that were used for AP pelvis radiography is (13.6- $35.38 \mathrm{mAs}$ ). The current average values of the $\mathrm{mAs}$ are almost similar to those reported in literature [6-10]. The SID recorded for AP pelvis radiography is ranged from $100 \mathrm{~cm} 123 \mathrm{~cm}$.
Patient ESD is presented in table (5). From this table, it can be seen that lowest ESD value was reported at ASTH with a value of $0.6 \mathrm{mGy}$, whereas the highest ESD value was reported at AHGA (1) with $4.14 \mathrm{mGy}$. The range of the average value of the ESD for AP pelvis examination across the seven units is from $0.81 \mathrm{mGy}$ to $3.4 \mathrm{mGy}$. 


\begin{tabular}{l|lr|ll|ll} 
& ISRA (India) & $=\mathbf{1 . 3 4 4}$ & SIS (USA) & $=\mathbf{0 . 9 1 2}$ & ICV (Poland) & $=\mathbf{6 . 6 3 0}$ \\
Impact Factor: & ISI (Dubai, UAE) $=\mathbf{0 . 8 2 9}$ & PUHЦ (Russia) $=\mathbf{0 . 1 5 6}$ & PIF (India) & $=\mathbf{1 . 9 4 0}$ \\
& GIF (Australia) & $\mathbf{0 . 5 6 4}$ & ESJI (KZ) & $=4.102$ & IBI (India) & $=\mathbf{4 . 2 6 0}$ \\
& JIF & $=\mathbf{1 . 5 0 0}$ & SJIF (Morocco) & $=2.031$ & & \\
\hline
\end{tabular}

Table 5.

This table presents, minimum, maximum, average and the standard deviation (SD) of the ESD (mGy) for pelvis X-ray examination across the studied hospitals.

\begin{tabular}{|c|c|c|c|c|c|c|}
\hline $\begin{array}{c}\text { Hospital } \\
\text { code }\end{array}$ & $\begin{array}{c}\text { Patient } \\
\text { number }\end{array}$ & Minimum & Maximum & Average & \pm SD & Max/Min \\
\hline ASTH & 13 & 0.6 & 1.14 & 0.81 & 0.16 & 1.9 \\
\hline AHGH (1) & 13 & 2.68 & 4.14 & 3.4 & 0.36 & 1.54 \\
\hline AHGH (2) & 14 & 1.9 & 3.55 & 2.7 & 0.47 & 1.86 \\
\hline AZH (1) & 13 & 0.89 & 2.48 & 1.66 & 0.52 & 2.7 \\
\hline AZH (2) & 13 & 1.79 & 5.91 & 3 & 0.99 & 3.3 \\
\hline AFAH(1) & 14 & 2.21 & 3.4 & 2.59 & 0.54 & 1.53 \\
\hline AFAH (2) & 13 & 1.9 & 2.85 & 2.3 & 0.4 & 1.5 \\
\hline * and ** represent the number of the room in a given hospital; SD represents standard deviation \\
\hline
\end{tabular}

\section{Discussion}

Monitoring the radiation dose for those patients undergoing routine radiographic X-ray examinations is of high importance from a radiation protection point of view. The latter argument is based on the fact that no safe dose ever no matter how small when considering the 'Linear No threshold Theory' (LNT). Therefore, attempts should be carried out to reduce the radiation dose and subsequently to reduce the patient radiation risk [21].

Examining the results of this work reveals that there was a clear variation in the calculated ESD whether among different hospitals or sometimes among the same hospital as evidenced by the SD (range: $\pm 0.0 .16- \pm 0.99$ ). Another evidence for the dose variation is demonstrated by the data of the ratio of the maximum to minimum of the ESD (table 5). For example, the ratio of $\mathrm{max} / \mathrm{min}$ of the ESD demonstrates that max value is around three times that of the minimum at AZH (2), while the lowest ratio is in AFAH (2) at 1.5 times. However, the range of the ratio of this study is lower than that reported for pelvis radiography in a previous study [22], while it is almost comparable to ratio of the $\mathrm{max} / \mathrm{min}$ reported in [9].

By way of comparison, the results of ESD for AP pelvis demonstrate that the average ESD for the five out of seven of the X-ray units was higher than those reported by UNSCEAR report- 2010 [23] for AP pelvis using computed radiography imaging equipment (see figure 2). However, the results demonstrates that the patients doses were a almost lower than that reported by UK-surevy-2010 for six $\mathrm{X}$-ray units out of seven ones except at one unit (i.e. AHGH (1)) where the ESD value was slightly higher than that reported in the UK [6]. High patient dose at AHGH (1) as compared to other local units and other international reported data on the doses could be attributed to the high $\mathrm{mAs}$ settings used together with high X-ray output (table 3).

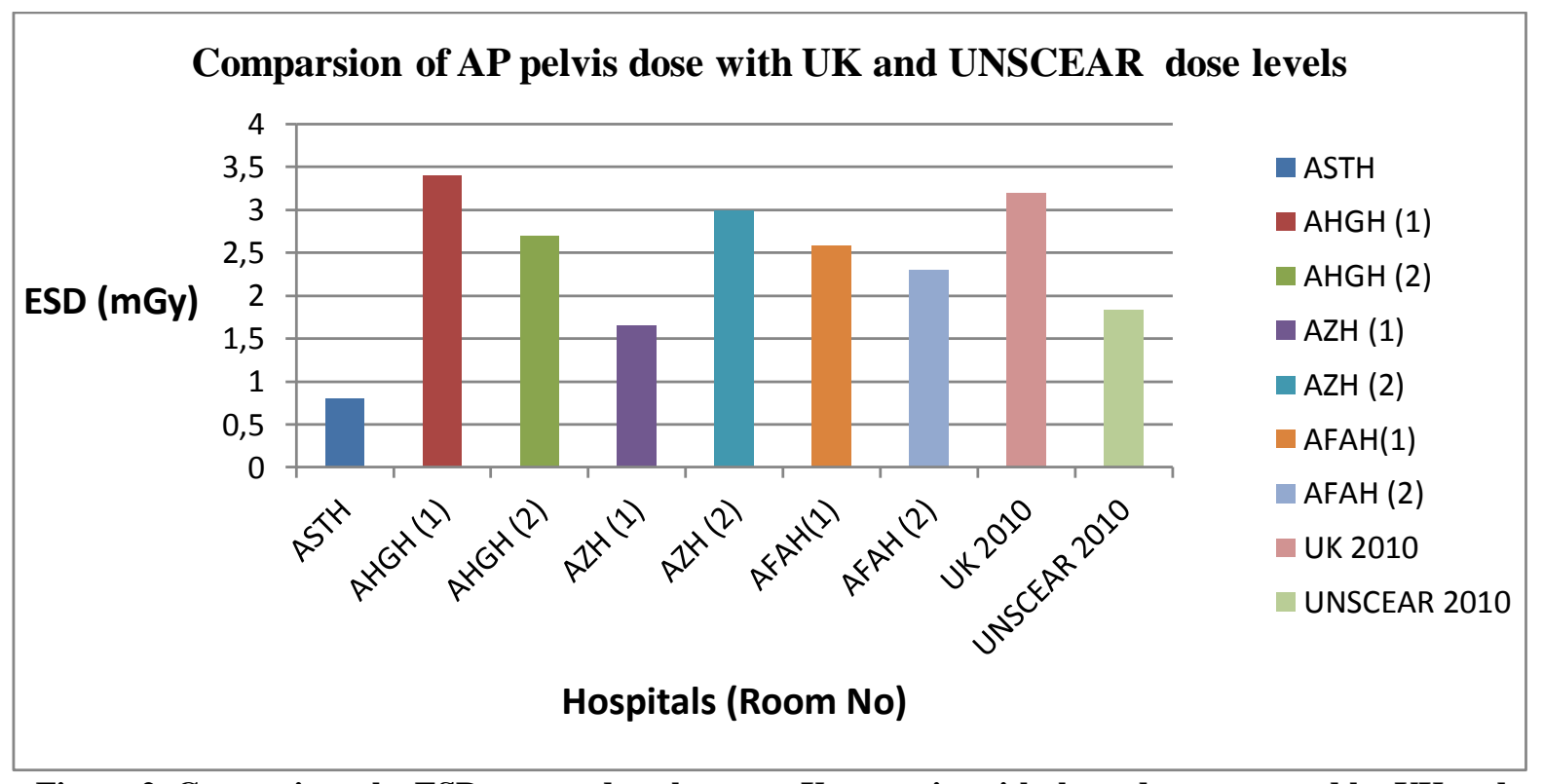

Figure 2. Comparison the ESD reported at the seven $X$-ray units with those doses reported by UK and UNSCEAR for AP pelvis. 
On the other hand, comparing the doses obtained by this study with the patients' doses undergoing pelvis radiography of the neighboring countries and other developing countries reveals that in the Saudi Arabia [24], the dose was higher than the doses calculated in all the X-ray units considered in this study (e.g. $5.41 \mathrm{mGy}$ ). This could be due to the high mAs used in the Saudi Arabia study (e.g. 80 $\mathrm{mAs}$ ). However, a recent study in Iran [25], the ESD of pelvis projection was reported to be lower than the doses calculated in six units out of seven and higher than one local unit (e.g. $1.47 \mathrm{mGy}$ ). Examining this case demonstrates that the Iranian hospitals are using approximately recommended level of the exposure factors together with achieving a regular quality control testing which our radiology departments may lack when compared with that of Iran. In a study conducted in Ghana (2014)[26], the AP pelvis ESD was reported to be considerably lower than the ESD obtained by the current study (i.e. 6 out of 7 units) by around $61 \%$ when compared with the highest ESD values reported in this study. This low dose level in Ghana can be clearly attributed to the low exposure settings adopted by Ghanaian operators.

However, another similar two studies conducted in Nepal and Ghana to assess the AP pelvis patients' dose in 2016 and 2013 respectively $[8,27]$ reveal that the ESD values were almost comparable to this study ESD except at two units in Ghana were the dose were extremely higher than this study and the international published levels $[6,23]$. Finally, a recent study conducted in India in 2017 [28] demonstrates that ESD for pelvis radiography was higher than the ones calculated in this study (e.g. average ESD $4.33 \mathrm{mGy}$ ).

The variations exist in the ESD among different hospitals and sometimes among the same X-ray unit for the same X-ray examination is an issue that needs to be discussed [29]. The latter argument is based on the fact that the variability in the patient exposure should be reduced to a minimum level aiming to achieve the quality assurance/control goals within the diagnostic X-ray units. To achieve these goals, it is important to periodically assess the patient dose and then to find the measure of keeping it as low as reasonably possible [30]. In practice, there are a number of causes behind these variations. For instance, setting different exposure factors among different X-ray units for the same X-ray projection would lead to different radiation exposure [31]; operators with different experience levels may cause the variability in the radiographic practice; finally, patients' sizes and could also impose certain limitations that can be reflected on the patients dose consistency at different units [32].

\section{Conclusion}

The radiation dose was calculated for those patients undergoing AP pelvis radiographic examination at the main hospitals of Al Najaf city. According to the results, the average ESDs values were almost comparable to those reported in UK survey for the majority of Najaf X-ray units, and higher than that reported by UNSCEAR for CR technology. A clear variation in setting the exposure factors for this X-ray projection was identified. The results of this study can be used as a baseline for future dosimetry assessment. Finally, to ensure that the patient dose is kept at the controlled level, equipment quality control testing together with performing a training course for operators is highly recommended.

\section{Acknowledgement}

The authors would like to thank the staff of faculty of Sciences-University of Kufa for their support. Also, we would like to thank all the radiologists and the radiographers who are working in Al Najaf Major hospitals who have directly and indirectly contributed to the production of this paper.

\section{References:}

1. Toosi MTB, Asadinezhad M. (2007) Local diagnostic reference levels for some common diagnostic X-ray examinations in Tehran county of Iran. Radiation Protection Dosimetry.2007;124(2): 137-144.

2. (2007) International Commission on Radiation Protection (ICRP). The 2007 Recommendations of the International Commission on Radiological Protection.ICRP Publication 103. Annals of ICRP. 2007;37(2-4):1-332.
3. (2018) Optimization of the radiological protection of the patients undergoing radiography, fluoroscopy and computed tomography, final report of a coordinated research project in Africa, Asia and Eastern Europe, TECDOC-1423. International Atomic Energy Agency, Vienn.

4. Martin CJ. (2007) The importance of radiation quality for optimisation in radiology. 
Biomedical Imaging and Intervention Journal COMMENTARY. 2007;3(2):1-38.

5. Frank ED, Long BW, Smith BJ. (2012) Merrill's atlas of radiographic positioning \& procedures. 12 ed. Missouri: Mossby.; 2012.

6. Hart D,mHillier MC, Shrimpton PC. (2012) Dose to the patients from radiographic and fluoroscopic X-ray imaging procedures in the UK- 2010 Review. Chilton: Health Protection Agency 2012 Contract No.: HPA-CRCE-034.

7. Compagnon G, Pagan L and Bergamini C. (2005) Local diagnostic reference levels in standards X-ray examinations. Radiation protection dosimetry.2005; 113(1): 54-63.

8. Compagnon KO, Antwi WK, Scutt DN and Ward M. (2013) Patient Radiation Dose Assessment in Pelvic X-ray Examination in Ghana. OMICS Journal of Radiology. 2013; 2(8):1-5.

9. Khoshdel-Navi D, Shabestani-Monfared A, Deevband MR, Abdi R, Nabahati M. (2016) Local-Reference Patient Dose Evaluation in Conventional Radiography Examinations in Mazandaran, Iran. Journal of Biomedical Physics and Engineering.2016; 6(2):61-70.

10. Rasuli B, Mahmoud-Pashazadeh A, Ghorbani M, Juybari RT, Naserpour M. (2017) Patient dose measurement in common medical X-ray examinations and propose the first local dose reference levels to diagnostic radiology in Iran. Polish Journal of Medical Physics and Engineering. 2017; 23(3): 67-71.

11. Mraity H, Hogg P, England A. (2017) Gonad dose in AP pelvis radiography: Impact of anode heel orientation. radiography. 2017;23(1):14-8.

12. Compagnon KO, Antwi WK, Scutt DN and Ward M. (2005) Optimization of patient radiation protection in pelvic X-ray examination in Ghana. Radiation protection dosimetry.2005; 13(4):160-171

13. England A, Evans P, Harding L, Taylor EM, Charnock P, Williams G. (2015) Increasing Source-to-Image Distance to Reduce Radiation Dose From Digital Radiography Pelvic Examinations. Radiologic technology. 2015;86(3):246-56.

14. Honey I, Hogg P. (2012) Balancing radiation dose and image quality in diagnostic imaging. Radiography. 2012;18(1):1-2.

15. (2007) IAEA. Dosimetry in diagnostic radiology: an international code of. IAEATechnical report series No.457; Vienna: IAEA. 2007.

16. (1996) European Commission (EC). European guidelines on quality criteria for diagnostic radiographic images: (EUR 16260 EN). Brussels: EC, 1996.

17. Herath L, Chandrasiri I, Senavirathne SA and Rosairo S. (2015) Entrance Surface Dose
Assessment for Postero-Anterior Erect Chest Xray Examinations of Adult Patients in a Selected Teaching Hospital in Sri Lanka. Proceedings of 8th International Research Conference, KDU, Published November. 2015; 21-25.

18. Suliman II and Mohammedzein TS. (2014) Estimation of adult patient doses for common diagnostic X-ray examinations in Wad-madani, Sudan: derivation of local diagnostic reference levels. Australasian Physical and Engineering Science in Medicine.2014; 32(2): 425-429.

19. Parry R, Glaze SA, Archer BR. (1999) The AAPM/RSNA Physics Tutorial for Residents Typical patient radiation doses in diagnostic radiology. Radiographics. 1999; 19:1289-302.

20. Suliman I I, Abbas N and Habbani FI. (2007) Entrance surface doses to patients undergoing selected diagnostic X-ray examinations in Sudan. Radiation Protection Dosimetry. 2007; 123(2): 209-214.

21. Hall E, Brenner D. (2014) Cancer risks from diagnosticradiology. The British journal of radiology. 2014.

22. Suliman II and Mohammedzein TS. (2014) Estimation of adult patient doses for common diagnostic X-ray examinations in Wad-madani, Sudan: derivation of local diagnostic reference levels. Australasian Physical and Engineering Science in Medicine.2014; 32(2): 425-429.

23. (2010) United Nations, Sources and Effects of Ionizing Radiation (Report to the General Assembly), Scientific Committee on the Effects of Atomic Radiation (UNSCEAR2008Volume1), UN, New York (2010).

24. Taha MT, Al-Ghorabie FH, Kutbi RA, Saib WK. (2015) Assessment of entrance skin doses for patients undergoing diagnostic X-ray examinations in King Abdullah Medical City, Makkah, KSA. Journal of Radiation Research and Applied Sciences. 2015;8 (1): 100-103.

25. Zarghani H, Bahreyni Toossi MT. (2018) Local Diagnostic Reference Levels for Some Common Diagnostic X-Ray Examinations In Sabzevar County of Iran. Iranian Journal of Medical Physics.2018;15(1):62-65.

26. Ofori K, Gordon SW, Akrobortu E, Ampene AA, Darko EO. (2014) Estimation of adult patient doses for selected X-ray diagnostic examinations. Journal of Radiation Research and Applied Sciences.2014; 7(4): 459-462.

27. Mahato NK, Banjade BJ, Kuttner S, Monsen E, Solstad H, Bhatt C. (2016) Measurement of Entrance surface dose of chest and pelvis: A study with the use of thermoluminescent dosimeter. Nepal Medical College Journal. 2016; 18(3-4): 137-140.

28. Uniya SC, Chaturvedi V, Sharma SD, Raghuvanshi S. (2017) Estimation of entrance 


\begin{tabular}{|c|c|c|c|c|c|c|}
\hline Impact Factor: & $\begin{array}{l}\text { ISRA (India) } \\
\text { ISI (Dubai, UAE } \\
\text { GIF (Australia) } \\
\text { JIF }\end{array}$ & $\begin{array}{l}=1.344 \\
=0.829 \\
=0.564 \\
=1.500\end{array}$ & $\begin{array}{l}\text { SIS (USA) } \\
\text { PИНЦ (Russia) } \\
\text { ESJI (KZ) } \\
\text { SJIF (Morocco) }\end{array}$ & $\begin{array}{l}=0.912 \\
=0.156 \\
=4.102 \\
=2.031\end{array}$ & $\begin{array}{l}\text { ICV (Poland) } \\
\text { PIF (India) } \\
\text { IBI (India) }\end{array}$ & $\begin{array}{l}=6.630 \\
=1.940 \\
=4.260\end{array}$ \\
\hline
\end{tabular}

surface air kerma due to diagnostic X-ray examinations of adult patients in Uttarakhand, India and establishment of local diagnostic reference levels. Australas Phys Eng Sci Med. 2017; 40(3):687-694.

29. (1996) European Commission (EC). European guidelines on quality criteria for diagnostic radiographic images: (EUR 16260 EN). Brussels: EC, 1996.

30. Shahbazi-Gahrouei D, BaradaranGhahfarokhiM. (2012) Investigation of patient dose from common radiology examinations in
Isfahan, Iran. Advanced Biomedical Research. 2012;1:11.

31. Rasuli B, Ghorbani M, Juybari RT. (2016) Radiation dose measurement for patients undergoing common spine medical $\mathrm{x}$-ray examinations and proposed local diagnostic reference levels. Radiation Measurements. 2016;87:29-34.

32. Suliman I I, Abbas N and Habbani FI. (2007) Entrance surface doses to patients undergoing selected diagnostic X-ray examinations in Sudan. Radiation Protection Dosimetry. 2007; 123(2): 209-214. 